\title{
Problem-oriented Teaching Mode based on Data Mining Technology in the Sports Psychology Classroom
}

\author{
https://doi.org/10.3991/ijet.v16i20.26411 \\ Guomeng Zhang ${ }^{1}$, Siyuan $\mathrm{Chen}^{2}\left({ }^{\bowtie}\right)$ \\ ${ }^{1}$ Changzhou Vocational Institute of Mechatronic Technology, Changzhou, China \\ ${ }^{2}$ Nanjing University Jinling College, Nanjing, China \\ chensiyuan@jlxy.nju.edu.cn
}

\begin{abstract}
Sports psychology is a branch of psychology and is a sports course that takes both theory and practice into account. It is not only an integral part of the talent training curriculum system of sports colleges and universities, but also a basic compulsory course for social sports majors in comprehensive universities. Sports psychology has currently become one of the significant theories in PE teaching, which not only guides PE teaching, but also helps solve existing problems in PE teaching and drives the development of PE teaching. Subject to the impact of traditional education mode and educational concept, etc., however, there are some problems in the existing the teaching of sports psychology, such as students' low interest, poor initiative and poor educational effect. To raise students' learning interest, this paper selected a problemoriented modular teaching mode, and applied it to the sports psychology classroom, to improve the learning effect. In this study, we first used data mining technology to build an anxiety prediction model and then identified a problem to be solved. After that, the problem was designed and analyzed, the known problem was confirmed, new information was collected, old and new knowledge was integrated, until the problem was finally solved. On this basis, based on virtual simulation technology, an experimental simulation teaching system for sports psychology was presented. It was found through research that the problems-oriented teaching mode can significantly enhance the effect of sports psychology and PE teaching and increase students' learning initiative. The learning effect was significantly better than that of traditional teaching methods.
\end{abstract}

Keywords—Problem-oriented, data mining technology, prediction model, sports psychology

\section{$1 \quad$ Introduction}

Physical education has long been ignored due to the influence of exam-oriented education. Students don't have a high interest in physical education and their athletic willpower is weak. In addition, affected by the idea of "technology centralism", PE teaching still rests on in specific physical exercise and neglects students' interest in physical education and their emotional needs. This greatly impairs the effect of PE 
teaching. In the meantime, due to the limitation of sports venue and the impact of teaching idea, etc., PE teaching often attends to one thing and loses another. Consequently, the exercise load can't meet the standard and it is hard to truly achieve the ideal teaching effect [1]. What's more, the current physical education methods are monotonous, principally the explanation of PE teachers and then demonstration and exercise, etc. The whole PE teaching atmosphere is dull, and students' learning initiative is low. With this in mind, to stimulate students' learning interest in sports, improve the effect of PE teaching in a targeted way and cultivate students' ability of sports activities, it is necessary to introduce sports psychology theory into PE teaching, according to students' characteristics. Since the existing PE teaching problems are concentrated, and also to solve these problems quickly, it is imperative to apply the theory of sports psychology to PE teaching.

There are three innovation points in this paper. First of all, the innovation in research angle, that is, when sports psychology is applied to PE teaching, a problemoriented modular teaching mode is employed, that is, according to the teaching goal, PE teachers sets barrier-passing questions to advance PE teaching tasks. This kind of modular teaching mode centered on problem solving will greatly inspire students' sense of participation in PE learning and promote their interest in sports. Secondly, the innovation in research content. When explaining how to approach the teaching of sports psychology based on the problem-oriented modular teaching mode, this paper introduces the teaching method of mental health teaching games-assisted sports psychology. Specifically, we introduce mental health educational games and weaken virtual simulation, to make students explore on their own, through an immersive and experiential learning mode, stimulate their learning motivation and enhance students' physical and mental health. Thirdly, the innovation in research method. In order to improve the teaching of sports psychology based on the problem-oriented modular teaching mode, this paper sets up an anxiety prediction model using data mining technology and applies it to practical teaching, to identify existing problems in the implementation of sports psychology based on the problem-oriented modular teaching mode, make improvements in time and improve the effect of PE teaching.

\section{State of the art}

"Problem-oriented teaching", also known as "problem-based teaching", was originated at Harvard Medical School in the United States, and later popularized in many medical schools. At present, many colleges and universities, including educational colleges, business colleges and engineering colleges, are attempting this teaching mode. This mode has also harvested the recognition of teachers in many subjects in practice. Among them, Rodzalan et al. [2] considered that the problem-oriented teaching mode enabled learners to apply the knowledge and skills they have learned, combine theory with practice, and develop a feasible program to solve the problem. Wiek et al. [3] drew up a PBL teaching reform plan based on PBL and applied it in Arizona State University's School of Sustainability (SOS). The results indicated that the PBL teaching reform turned out a great success, improving students' learning initiative and 
strengthening their ability to solve problems. Bilgin et al. [4] in a Primary School Education Department of a State University in Turkey, applied PBL to the professional courses of Primary School Education Department. After random grouping, the experimental group $(\mathrm{n}=33)$ was taught by PBL method, while the control group $(\mathrm{n}=33)$ was taught by the traditional teaching method. The science and technology teaching achievement test (STTAT) and self-efficacy belief scale (SEBS) were taken as pre-test and post-test scales. The results suggested that the SEBS and STTAT scores in the experimental group were higher. Zarouk et al. [5] applied PBL teaching method to biology course in the University, with the aim of demonstrating the benefits of redesigning a standard to create a more effective learning environment. With use of the PBL method, students showed improvement in the areas of self-confidence, lab technical skills, and interest in STEM-related fields and, most of all, the students showed a high level of performance and satisfaction. Phusavat et al. aimed to develop a pedagogy which would help a school become a workplace for learning and professional development. The team designed PBL as a teaching case, i.e., peer-learning community (PLC). This case was applied to Mattayom Suwitserianusorn School of Bangkok University. The experimental results showed that PLC teaching can help improve the relationship between students' motivation, professional emotion and cognition. In a word, the current PBL model has been accepted by the educational community, and colleges and universities in Britain, Canada, Australia and the Netherlands, etc. are also using or introducing PBL in their education [6].

With PBL moving from the original the medical education field to other disciplines, this teaching mode has gradually been accepted and used by Chinese educators. Zhang [7] explored the application of the problem-based teaching method in Chinese teaching. By taking the teaching of modern Chinese as an example, the author contended through research that the problem-based teaching method can exert students' subjectivity, liven the atmosphere in the classroom, and inspire the students' problem-thinking awareness. It was very significant for students' construction and refinement of rhetoric knowledge structure, the nurturing of their innovation awareness and the enhancement of their integrated quality. Nie [8] investigated the application of the problem-oriented teaching mode in the coaching of pediatric nursing. The author specifically selected 52 interns to study the teaching effect of problem-oriented teaching based on the coaching mode in virtual reality. The results indicated that the problem-oriented teaching integrating a virtual situation mode can significantly enhance the theoretical and operational level of interns, and remarkably improve their learning initiative and learning confidence, so that the level of pediatric nursing can be improved as a whole. From here we see that scholars generally agree that the problem-oriented teaching mode is a vitally effective teaching mode.

Sports psychology is currently an important subject in the field of physical education. To drive the development of this subject and its application in sports, researchers have done a lot of research on sports psychology. Many of them probe into sports events, talent draft and PE teaching, etc. using the theory and practice of sports psychology, and all of the results verify the important significance of the theory and practice of sports psychology for the practice of sports. Nevertheless, there are few studies on how to improve the teaching of sports psychology. Zhao [9] propounded the new 
teaching mode of "binary classroom", that is, to divide classroom education in half. In half of the time, teachers imparted knowledge to students. In the other half of the time, students were allowed to act freely, to learn or ask questions to teachers through discussion. This teaching mode also gave students plenty of time to review the lessons taught by teachers, which was favorable for their learning. As evidenced by relevant research, sports psychology was a subject with strong applicability, requiring students to understand the basic theoretical knowledge of sports psychology and use it flexibly to guide existing sports learning. However, subject to the limitation of subjective or objective conditions, most schools adopt the form of instruction and demonstration in the teaching of this course, and seldom use learning methods like problem-oriented learning. The consequence is that the teaching methods are monotonous, and the differences and learning needs of students are often ignored. There is a lack of real-time communication and interaction between students and teachers, and students don't have a high initiative for participating in teaching activities. Students don't have enough opportunities to combine theory with practice, learn knowledge without being able to use it. These phenomena reveal that the teaching of modern sports psychology can't live up to teaching requirements in the new era, and the teaching reform of this course is hardpressed. With this in mind, this paper attempts to build an anxiety prediction model innovatively based on data mining technology, and apply it to teaching as a practice content of sports psychology. At the same time, based on virtual interaction theory and theories related to sports psychology, etc., this paper builds a problem-oriented teaching mode, introduces a teaching environment with virtual simulation, and applies it to sports psychology, with a view to improve the effect of PE teaching, stimulate students' interest in PE learning, and provide a reference for the teaching of other psychological courses.

\section{Application of the Problem-oriented Teaching Mode in the Course of Sports Psychology}

\subsection{Application of the Problem-oriented Approach in Teaching}

The problem-oriented teaching mode has been continuously practiced in the teaching of a variety of subjects. Centered on learners and focused on a given issue, this mode guides students to make full use of theory and practice and arrive at problem solutions, while learning knowledge and skills. The teaching effect of this mode has also been approved by many teachers [10]. In effect, the problem-oriented teaching mode is not only a teaching mode, but also a curriculum development model. This model can also be fully employed in the teaching of sports psychology. The concrete framework is shown in Fig. 1 below: 




Fig. 1. Basic Framework of the Problem-oriented Teaching Mode

In the problem-oriented teaching mode, the whole process from identifying a problem, analyzing the problem, producing a hypothesis, confirming the known problem, confirming required information, confirming resources, collecting new information, integrating old and new knowledge, and finally solving the problem is designed to apply the learned knowledge to solve the problem. If there is no effective solution, the learning will be repeated until the problem is solved. This teaching mode is applied to the course of sports psychology specifically. When designing a teaching goal, teachers must first put forward a practical problem, in which students can intervene preliminarily and solve, explain relevant theoretical knowledge and illuminate corresponding cases. After that students are asked to analyze this problem, based on relevant theories. According to the new and old theoretical knowledge and related resources, the problem is finally solved, so that students can grasp a given sports skill. If the problem is not effectively solved, teachers can supplement relevant skills or make a demonstration until students solve the problem. After solving the problem, teachers should propose target skills for the future. It can thus be seen that the problemoriented teaching mode is a student-centered mode that helps students learn knowledge and skills by solving problems. When applied in sports psychology, it also fully motivates students to participate in PE learning and achieves the purpose of PE teaching.

\subsection{Application of the Anxiety Prediction Model Based on Data Mining Technology in Practical Course}

The key to the application of the problem-oriented teaching mode to sports psychology is that PE teachers should be able to raise a problem to be solved. This problem mustn't trigger students' anxiety, but inspire their interest in exploration. Thus, when PE teachers design this problem and implement the problem-oriented teaching mode, they should predict the anxiety of students under each problem using relevant technologies. Among these technologies, data mining technology is an advanced and scientific one. 
As a manner of fact, influenced by traditional exam-oriented education, sports and physical education have long been ignored. Many students also mistakenly think that their athletic gene is underdeveloped. When being asked to solve a problem in PE teaching, they usually feel anxious, which is not favorable for the solution of problem. Thus, in the teaching process of sports psychology, our study should first predict this kind of anxiety in PE teaching. Specifically, the prediction can be made as shown in Fig. 2 below.

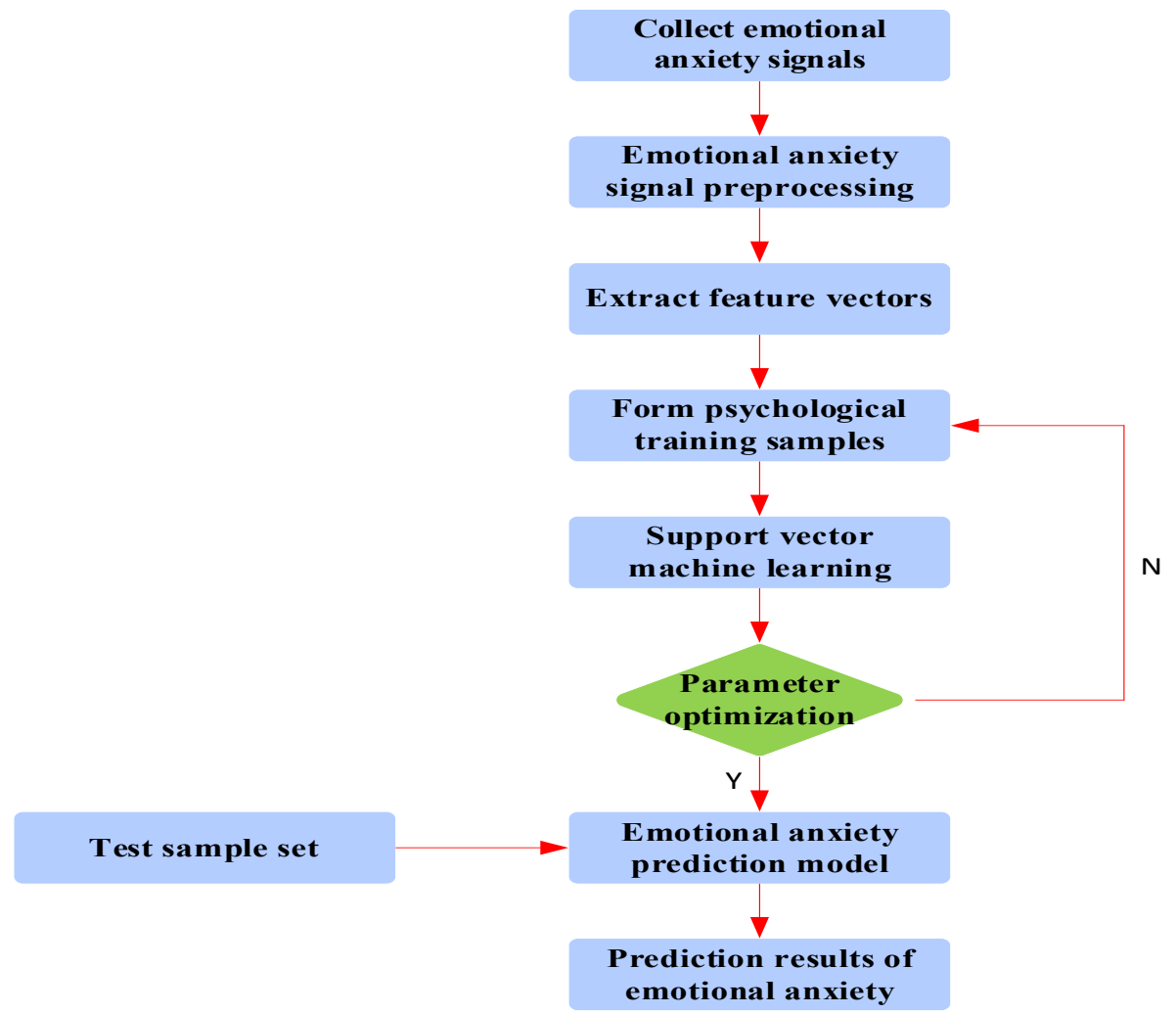

Fig. 2. The Process of Anxiety Prediction Based on Data Mining Technology

As can be seen from Fig. 2, the building of the whole anxiety prediction model based on data mining technology is mainly divided into the following four steps:

1. The collection of anxiety signals

Generally speaking, when an individual experiences anxiety, his/her language will change accordingly, such as becoming impatient, restless and nervous, etc. So our study collected the language signals of respondents as the anxiety signals. To be specific, the author collected language signals by using TMS320C6713 and converted these signals into digital signals by using a digital-to-analog converter. 
2. The preprocessing of anxiety signals

To minimize noise in the collected anxiety signals and avoid adverse effects on subsequent processing, this paper preprocessed the collected anxiety signals by means of wavelet transform. If the Fourier transform satisfied the condition in Eq. (1), then $\psi(t)$ was a wavelet function (mother wavelet).

$$
C_{\psi}=\int_{-\infty}^{+\infty}|\psi(\bar{w})|^{2} w^{-1} d w
$$

Where $\psi(t)$ was an integrable function. The mean of this function satisfied the following condition:

$$
\int_{-\infty}^{+\infty} \psi(t) d t=0
$$

That is, the plus or minus alternation of $\psi(t)$ partly fluctuated. This function can be further transformed into Eq. (3) as follows.

$$
\psi_{a, b}(t)=(a)^{-\frac{1}{2}} \psi\left(\frac{t-b}{a}\right)
$$

The continuous wavelet of the anxiety signal $f(t)$ can be derived on the basis of Eq. (3), that is, the projection of the multi-scale translation signal of $\psi_{a, b}(t)$

$$
W_{f}(a, b)=(a)^{-\frac{1}{2}} \int_{R} f(t) \psi\left(\frac{t-b}{a}\right) d t=\int_{-\infty}^{+\infty} f(t) \psi_{a, b}(t) d t
$$

After further transformation of continuous wavelet, we can get:

$$
\left\{\begin{array}{c}
W_{f}(a, b)=W_{f_{1}}(a, b)+W_{f_{2}}(a, b) \\
f(t)=\alpha f_{1}(t)+\beta f_{2}(t)
\end{array}\right.
$$

Through the above processing, the wavelet transform produced many wavelet signals, i.e., their coefficients were wavelet coefficients. These wavelet coefficients can be categories into wavelet coefficients with noise and wavelet coefficients with clean anxiety signals. By comparing all wavelet coefficients with the optimal threshold, noise was derived preliminarily. And these wavelet coefficients were set to 0 and eventually reconstructed through inverse wavelet transform, so that clean anxiety signals can be obtained and effective data can be proffered for the construction of an anxiety prediction model.

3. The extraction of feature vector

After getting clean anxiety signals, this paper extracted short-term zero cross rate and short-term energy features, according to theories related to psychology.

In terms of the extraction of short-term zero cross rate features, the number of times anxiety signals crosses the horizontal axis was calculated. For details, see Eq. (6) below:

$$
Z_{i}=\frac{1}{2} \sum_{n=1}^{L}\left|\operatorname{sgn}\left(y_{i}(n)\right)-\operatorname{sgn}\left(y_{i}(n-1)\right)\right|
$$


Where the sign function $\operatorname{sgn}(x)$ satisfied $\operatorname{sgn}(x)=\left\{\begin{array}{c}1, x \geq 0 \\ -1, x<0\end{array}\right.$

The short-term energy features processed the anxiety signals frame by frame. Specifically, they can be expressed as:

$$
E(i)=\sum_{n=1}^{L} y_{i}^{2}(n)
$$

Where $y_{i}(n)$ was the anxiety signal in the $i$ th frame, which can be calculated using the following equation:

$$
y_{i}(n)=w(n) * f((i-1) * i n c+n)
$$

Where inc was the frame shift of anxiety signal, and $w(n)$ was the window function of anxiety signal.

4. The learning of support vector machine

After the above feature extraction of anxiety signals, the training sample set was divided tentatively. Below, the sample parameters should be solved by data mining technology, to get an anxiety prediction model. The support vector machine (SVM) was a new type of data mining technology, which mainly modeled a given complex problem. Assumed that the data set of this problem was:

$$
\left\{\left(x_{1}, y_{1}\right),\left(x_{2}, y_{2}\right), \cdots\left(x_{n}, y_{n}\right)\right\}
$$

To begin with, a mapping function was adopted to map this data set, as shown in Eq. (9):

$$
f(x)=w * \varphi(x)+b
$$

According to the learning principle of minimal structural risk, the classification hyperplane built above satisfied the following condition:

$$
y_{i}\left(\varphi\left(x_{i}\right)+b\right) \geq 1
$$

In an effort to promoted the classification accuracy, this paper introduced a slack variable, so that the classification hyperplane can be transformed into the following problem:

$$
\begin{array}{cl} 
& \frac{1}{2} w \cdot w+C \sum_{i=1}^{n} \xi_{i} \\
\text { s.t. } & y_{i}\left(w \cdot x_{i}+b\right) \geq 1-\xi_{i}
\end{array}
$$

Where $\xi$ was the slack variable, $C$ was the penalty function. Lagrange algorithm was used to further process Eq. (11), as follows:

$$
\begin{gathered}
\frac{1}{2} \sum_{i=1}^{n} \alpha_{i} \alpha_{j} y_{i} y_{j}\left(\varphi\left(x_{i}\right) \varphi\left(x_{j}\right)\right)+\sum_{i=1}^{n} \alpha_{i} \\
\text { s.t. } \sum_{i=1}^{n} \alpha_{i} y_{i}=0
\end{gathered}
$$


A kernel function was led in,

$$
k\left(x_{i}, x_{j}\right)=\varphi\left(x_{i}\right) \varphi\left(x_{j}\right)=\exp \left(-\frac{\left\|x-x_{i}\right\|}{2 \sigma^{2}}\right)
$$

By substituting Eq. (13) into Eq. (12), we can get:

$$
\begin{gathered}
\frac{1}{2} \sum_{i=1}^{n} \alpha_{i} \alpha_{j} y_{i} y_{j} k\left(x_{i}, x_{j}\right)+\sum_{i=1}^{n} \alpha_{i} \\
\text { s.t. } \quad \sum_{i=1}^{n} \alpha_{i} y_{i}=0
\end{gathered}
$$

Meanwhile, the above optimal classification hyperplane can also be expressed as:

$$
f(x)=\sum_{i=1}^{n} \alpha_{i} y_{i} k\left(x_{i}, x_{j}\right)+b
$$

The above support vector machine was used to train the anxiety samples. If the parameters were the optimal, an anxiety prediction model can be obtained and the whole process of anxiety prediction can be finished, to provide a basis for PE teachers to design questions to lower students' anxiety.

\subsection{Application of the Problem-oriented Teaching Mode in the Virtual Course of Sports Psychology}

After setting specific questions, this paper established a virtual course of sports psychology based on the problem-oriented teaching mode. The specific design was shown in Fig. 3 below:



Fig. 3. Information Architecture of VR Sports Psychology 
In the interaction design of virtual system, it was usually needed to use information architecture to represent the interaction between various systems. In the above information architecture of VR sports psychology designed in this paper, from question lead-in, theoretical basis, technology-driven, to the interpretation of case, expansion and application, students were enabled to gradually solve a given problem in $\mathrm{PE}$ teaching and grasp a given sports skill through the learning of various modules in virtual reality.

1. Question lead-in: according to above results of anxiety prediction based on data mining technology, teachers set questions that students were interested in and less anxious about, created a problem situation and placed students into the situation they were facing, which can greatly enhance their learning interest.

2. Theoretical basis: to solve this problem, teachers should give theoretical guidance, so that students can learn the essence of the problem and gain a preliminary insight into relevant theories.

3. Technology-driven: in this part, teachers should provide available and most common resources and tools, and support students to solve this problem by demonstrating with certain movements.

4. Interpretation of case: to help students solve problems effectively, PE teachers can illustrate with concrete and typical cases to teach students how to use relevant tools and resources to solve problems, or enumerate some similar expansion solutions.

5. Expansion and application. Based on the above theoretical interpretation, technology-driven and interpretation results of case. In this part, PE teachers encourage students to output their own problem solutions and share these solutions.

PE teachers can adopt the information architecture of VR sports psychology shown in Fig. 3 above to approach the problem-oriented teaching of PE course, and teach relevant knowledge, by following the guide of this diagram. Fig. 4 and Fig. 5 are practice links of the application of anxiety prediction model in sports psychology, as well as the demonstration of sports psychology course integrating VR technology.

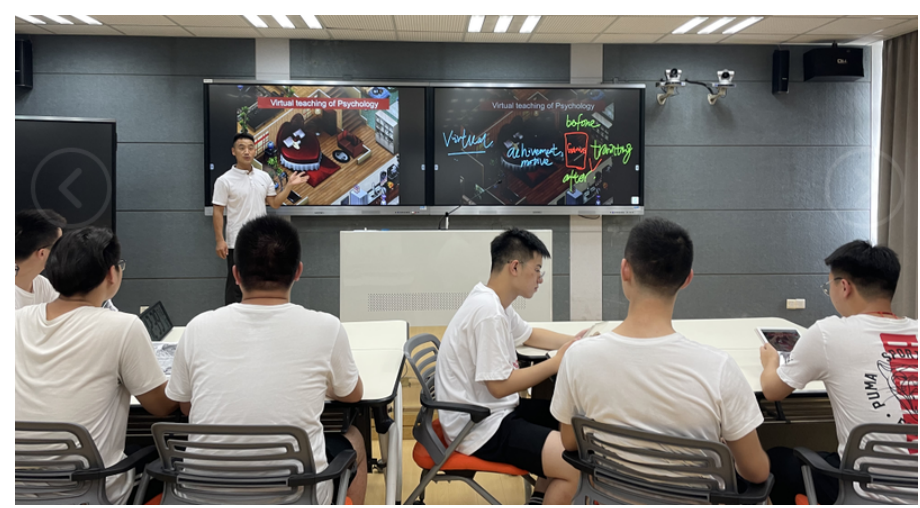

Fig. 4. Practice Links of the Application of Anxiety Prediction Model in Sports Psychology 




Fig. 5. The Integration of VR Technology in the Demonstration of Sports Psychology Course

\section{Teaching example and effect}

\subsection{Teaching example}

Based on the above design of problem-oriented sports psychology course, this paper established a virtual simulation teaching system with "three links and five modules". For details, see Fig. 6. Among them, the "three links" were research link, practice link and cooperation link, and the "five modules" were virtual training module, virtual reality experimental module, applied psychology experimental module, sports practice training module and anxiety prediction psychological experimental module. Fig. 7 shows the problem-oriented teaching process of sports psychology.

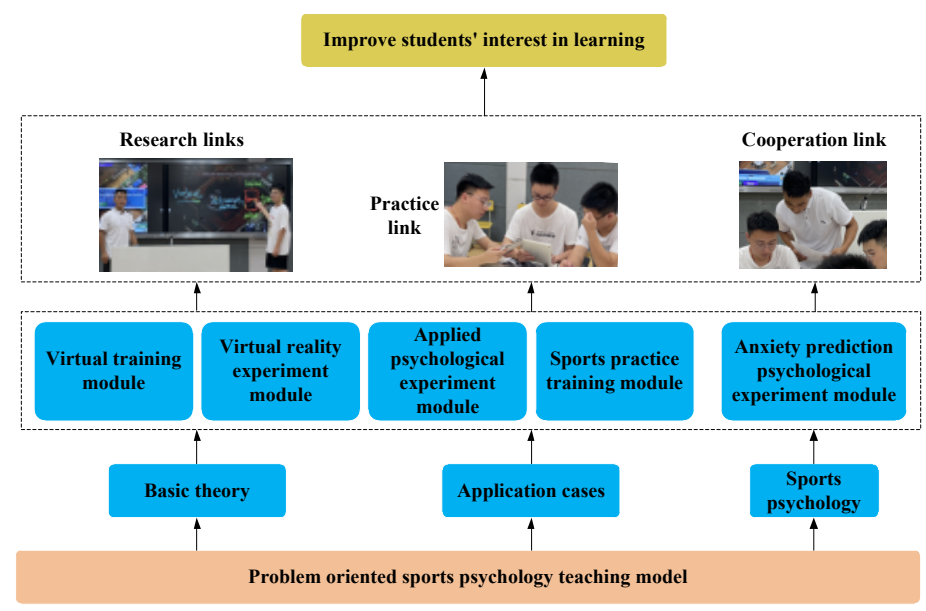

Fig. 6. The Problem-oriented VR Teaching System of Sports Psychology 
Virtual training module. This module was a module used for researching the skill field. In the problem-oriented the teaching of sports psychology mode, this module was mainly used to research and collect various psychologies of students in PE learning, help researchers find out teaching plans that can be adopted for psychological problems in the form of man-machine interaction, by simulating a variety of psychological symptoms and psychological counseling.

Virtual reality experimental module. The virtual reality experimental module used teaching plans that can be adopted in the virtual training module in the virtual teaching of sports psychology. By observing students' learning interest and learning effect, the effect of a given teaching plan was examined and the shortcomings of various teaching plans were identified, so that a correction scheme can be presented specifically.

Applied psychology experimental module. The applied psychology experimental module was based on the aforesaid research results of virtual practice training and virtual reality experiment, etc. and used the problem-oriented the teaching of sports psychology plan to concrete experimental teaching. By taking the form of experiment, this module examined the effectiveness of the problem-oriented the teaching of sports psychology plan by observing students' interest in PE learning and sports skills, etc.

Sports practice training module. By applying the experimental results of experimental module to practical training, the applied psychology training module examined the problem-oriented the teaching of sports psychology mode by observing and collecting the situation of practical training.

Anxiety prediction experimental module. An "anxiety prediction experiment" was built by using data mining technology, Flash and other information technologies. Teachers can access this module by logging in remotely, get classic anxiety cases, transcend the limitation of time and space and draw on advanced teaching experience.

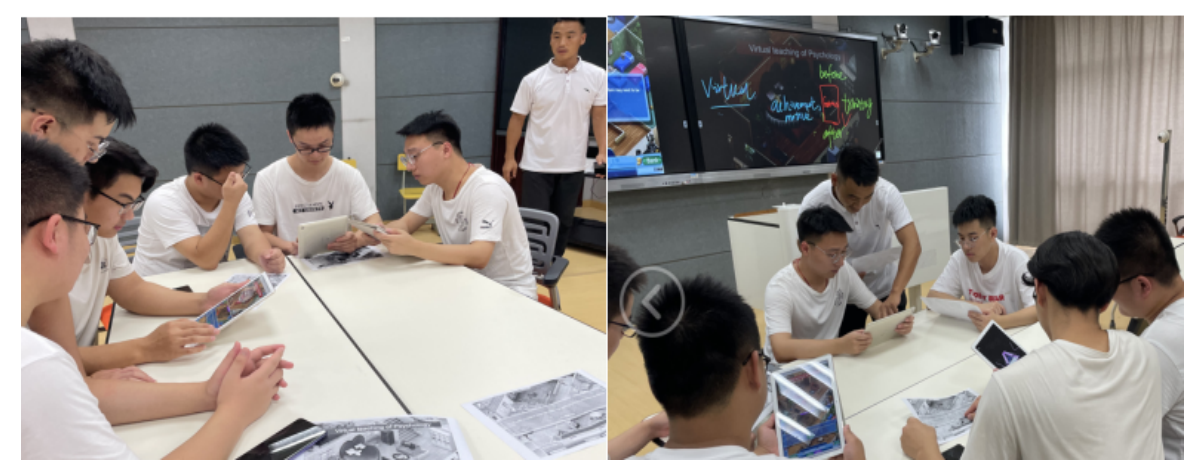

Fig. 7. The Problem-oriented Teaching Process of Sports Psychology

To examine the effectiveness of the problem-oriented teaching mode established in this study, we selected 100 sophomores as the research objects randomly and divided them into Groups A and B, according to the implementation of this teaching mode (or not). Among them, Group A was taught by the problem-oriented teaching mode of 
sports psychology, while Group B was taught by the traditional teaching mode. The gender composition of each group is shown in Table 1 below.

Table 1. Grouping

\begin{tabular}{|l|c|c|}
\hline & Observation Group: Group A & Control Group: Group B \\
\hline Male Students & 24 & 27 \\
\hline Female Students & 26 & 23 \\
\hline Total & 50 & 50 \\
\hline
\end{tabular}

From Table 1 above, Groups A and B had little differences in gender, and they were comparable, which eliminated the difference in teaching effectiveness as a result of gender difference.

Specifically speaking, for the observation group (Group A), virtual reality situation was adopted on the basis of relevant theoretical teaching. Concrete PE teaching was approached by using the problem-oriented teaching mode, that is, the teachers guided students to analyze problems, established a virtual situation and helped solve relevant problems, on the premise of learning relevant theoretical knowledge, observing demonstrative teaching and interpreting cases. For the control group (Group B), conventional teaching mode was adopted. By observing the teaching satisfaction and academic performance of two groups of students, we examined the effectiveness of the new the teaching of sports psychology mode applied in this study by evaluating the teaching mode.

\subsection{Teaching effect}

Students' teaching satisfaction. Through a questionnaire survey, our study collected students' satisfaction with these two teaching modes. The results suggested that the teaching satisfaction of the observation group was significantly higher than that of the control group, as shown in Table 2.

Table 2. Survey of Teaching Satisfaction (\%)

\begin{tabular}{|l|c|c|c|c|}
\hline & Satisfied & Generally Satisfied & Dissatisfied & Total Satisfaction \\
\hline Observation Group: Group A (n=50) & $23(46 \%)$ & $21(42 \%)$ & $6(12 \%)$ & $44(88 \%)$ \\
\hline Control Group: Group B $(\mathrm{n}=50)$ & $12(24 \%)$ & $19(38 \%)$ & $17(38 \%)$ & $31(62 \%)$ \\
\hline$\chi^{2}$ Value & & & & 6.1809 \\
\hline$P$ Value & & & & 0.0027 \\
\hline
\end{tabular}

As can be seen from Table 2, at the significance level of 5\%, the teaching satisfaction of the observation group was significantly higher than that of the control group, with a statistically significant difference. This implied that the problem-oriented teaching mode of sports psychology of simulation teaching mode with "three modules and five platforms" can effectively promote teaching satisfaction.

Academic performance. This paper also compared the final scores of two groups, and the results are shown in Table 3 below: 
Paper_-Problem-oriented Teaching Mode based on Data Mining Technology in the Sports Psychology...

Table 3. Comparison of Academic Performance between Two Groups

\begin{tabular}{|l|c|c|}
\hline Group & Sports Results & Theoretical Results \\
\hline Observation Group: Group A & $94.26 \pm_{3.12}$ & $95.01 \pm_{3.01}$ \\
\hline Control Group: Group B & $80.19 \pm 3.17$ & $82.33 \pm_{2.98}$ \\
\hline $\mathrm{t}$ value & 7.9140 & 6.1782 \\
\hline P value & 0.0009 & 0.0007 \\
\hline
\end{tabular}

As can be seen from Table 3, both the sports performance and theoretical performance of the observation group were significantly higher than those of the control group, implying that the problem-oriented the teaching of sports psychology mode can effectively improve students' performance.

Evaluation of teaching mode. In this paper, the teaching mode was evaluated by the results of questionnaire survey. The results are shown in Table 4 below:

Table 4. Evaluation Results of Two Teaching Modes

\begin{tabular}{|l|c|c|c|}
\hline \multicolumn{1}{|c|}{ Group } & \multicolumn{1}{|c|}{$\begin{array}{c}\text { Improve Learning } \\
\text { Initiative }\end{array}$} & $\begin{array}{c}\text { Enhance Learning } \\
\text { Confidence }\end{array}$ & $\begin{array}{c}\text { Improve Learning } \\
\text { Efficiency }\end{array}$ \\
\hline $\begin{array}{l}\text { Observation } \\
\text { Group: Group A }\end{array}$ & $1.69 \pm 0.27$ & $1.73 \pm 0.29$ & $1.32 \pm 0.18$ \\
\hline Control Group: Group B & $0.79 \pm 0.14$ & $0.83 \pm 0.15$ & $0.80 \pm 0.21$ \\
\hline t value & 11.009 & 6.294 & 7.092 \\
\hline P value & 0.000 & 0.009 & 0.007 \\
\hline
\end{tabular}

The results of questionnaire survey implied that the learning initiative, learning confidence and learning efficiency of students in the observation group were significantly higher than those in the control group, with a statistically significant difference for $\mathrm{P}<0.001$.

By summarizing students' teaching satisfaction, academic performance and evaluation results of teaching mode above, we can see that after the implementation of the problem-oriented teaching mode of sports psychology, students' interest in PE learning and academic performance were significantly improved. This teaching mode was an effective one, for the following reasons: according to the data collected by questionnaire, students were supportive of the use of the problem-oriented teaching strategy in the practical activities of this course, and they had a high degree of acceptance, believing that this strategy can inspire their learning interest, actively promote the internalization and transfer of knowledge, and expand students' thinking ability and problem-solving ability.

First of all, the limitation of the original traditional teaching was broken. Students, teachers and students were allowed to communicate with each other by using mobile phone and other mobile devices in their spare time. Moreover, since the training mode of this course was "theory + practice", in theory classes, teachers simply explained and summarized knowledge points, students didn't have a high degree of involved and the teaching in classroom was still predominated by teachers. In the teaching 
practice of our study, however, our team created a problem situation in classroom, assigned activity tasks and offered corresponding learning resources. Students were entirely placed in a subject position of learning. In this process, teachers played the role of organizer, facilitator and guide and help students complete activity tasks. Through our observation of teaching practice, students had a high degree of involvement, from the analysis of problem, the division of group tasks, autonomous learning and cooperative inquiry learning to the formation of final plan, and actively share and exchange their own ideas and listen to others' opinions. The effect of group cooperative learning was very prominent.

\section{Conclusions}

At the current stage, the teaching of sports psychology is still dominated by teachers' demonstration and students' repeated exercise. This teaching mode lowers students' learning interest, and makes it hard for students to get real improvement in their grades. To this end, this paper puts forward a problem-oriented teaching mode, and wages a teaching reform based on theories related to psychology. Specifically, we build an anxiety prediction model based on data mining technology and design relevant questions according to students' anxiety. After that, we design an information framework for VR sports psychology for PE teachers to approach PE teaching in line with the interaction design theory of virtual system. What's more, to verify the effectiveness of the problem-oriented teaching mode, our study also designs an experiment to verify the teaching effect. Through research, our study arrives at the following conclusions:

1. The problem-oriented teaching mode fully mobilizes students' enthusiasm and effectively improve the effect of PE teaching, from identifying a problem, analyzing the problem, producing a hypothesis, confirming the known problem, confirming required information, confirming resources, collecting new information, integrating old and new knowledge, and finally solving the problem. This teaching mode requires PE teachers to guide students to focus on problems.

2. The key of the problem-oriented teaching mode is the setting of problems to be solved. This can be done by the anxiety prediction model based on data mining technology. Teachers can decide whether to select a problem by measuring the anxiety of students under a certain problem.

3. Combined with the interaction design theory of virtual system, the information architecture of VR sports psychology from question lead-in, theoretical basis, technology-driven, to the interpretation of case, expansion and application enables students to gradually solve a given problem in PE teaching and master a given sports skill through the learning of various modules in virtual reality.

4. The result of teaching case analysis suggests that the problems-oriented teaching mode can significantly motivate students to participate in sports, improve their satisfaction with PE course and PE scores. Students also speak highly of this teaching mode. All of these imply that it is an effective teaching mode. 
Due to the limited research effort, however, this paper fails to design the details of the problem-oriented teaching model. Nor does it summarize the deficiencies in teaching. This should be further supplemented in future research. In a word, with the deepening of the teaching reform of sports psychology, the problem-oriented teaching mode in this paper will have a broad space for development when applied to sports psychology. The anxiety prediction model based on data mining technology designed in this paper is of great reference value in the practical teaching of sports psychology.

\section{References}

[1] Yin, Z.H., Shao, K. "Intelligent Physical Education" in Colleges and Universities: Dilemma, Practice, Reform. Journal of Shenyang Agricultural University (Social Sciences Edition), 2020, vol. 22(2), pp. 178-183.

[2] Rodzalan, S., Noor, N.M., Arif, L.M., \& Saat, M.M. Factors Influencing the Improvement of Students' Critical Thinking and Problem-Solving Skill: An Industrial Training Intervention. International Journal of Emerging Technologies in Learning, 2020, vol. 15(22), pp. 134-145. https://doi.org/10.3991/ijet.v15i22.16303

[3] Wiek, A., Xiong, A., Brundiers, K., et al. Integrating problem and project-based learning into sustainability programs: A case study on the school of sustainability at Arizona state university. International Journal of Sustainability in Higher Education, 2015, vol. 15(4), pp. 431-449. https://doi.org/10.1108/ijshe-02-2013-0013

[4] Bilgin, I., Karakuyu, Y., Ay, Y. The Effects of Project Based Learning on Undergraduate Students' Achievement and Self-Efficacy Beliefs Towards Science Teaching. Eurasia Journal of Mathematics, Science and Technology Education, 2015, vol. 11(3), pp. 469477. https://doi.org/10.12973/eurasia.2014.1015a

[5] Zarouk, M., Olivera, E., Peres, P., \& Khaldi, M. The impact of flipped project-based learning on self-regulation in higher education. International Journal of Emerging Technologies in Learning, 2020, vol. 15(17), pp. 127-147. https://doi.org/10.3991/ijet.v15i17.14135

[6] Phusavat, K., Hidayanto, A.N., Kess, P., et al. Integrating Design Thinking into peerlearning community. Journal of Workplace Learning, 2019, vol. 31(1), pp. 59-74. https://doi.org/10.1108/jwl-03-2018-0055

[7] Yang, M.M. The Application of PAD Class in Educational Psychology Teaching. Journal of Heilongjiang College of Education, 2017, vol. 36(8), pp. 35-37.

[8] Nie, F., Li, Y. Exploring the Application Effect of Problem-oriented Teaching Combined with Virtual Situation in Pediatric Nursing Teaching. China Health Industry, 2021, vol. 18(4), pp. 15-17

[9] Zhao, D. Application of dichotomy classroom in educational psychology teaching. Heilongjiang Science, 2018, vol. 9(11), pp. 116-117.

[10] Ruiz-Gallardo, J.R., Casta, O.S., Gómez-Alday, J.J., et al. Assessing student workload in Problem Based Learning: Relationships among teaching method, student workload and achievement. A case study in Natural Sciences. Teaching \& Teacher Education, 2011, vol. 27(3), pp. 619-627. https://doi.org/10.1016/j.tate.2010.11.001 
Paper_-Problem-oriented Teaching Mode based on Data Mining Technology in the Sports Psychology...

\section{Authors}

Guomeng Zhang is a Lecturer in Changzhou Vocational Institute of Mechatronic Technology, Changzhou, Jiangsu 213164, China. (Email: 346517910@qq.com). Sponsored by Qing Lan Project.

Siyuan Chen (Correspondence Author) is a Lecturer in Nanjing University Jinling College, Nanjing 210089, China.

Article submitted 2021-08-22. Resubmitted 2021-09-25. Final acceptance 2021-09-27. Final version published as submitted by the authors. 